\title{
A centralidade do trabalho para a construção da saúde*
}

\author{
Entrevista com Christophe Dejours, por Juliana de Oliveira Barros ${ }^{1}$ e Selma Lancman ${ }^{2}$
}

http://dx.doi.org/10.11606/issn.2238-6149.v27i2p228-235

$\mathrm{C}$ onsiderou-se relevante que o artigo de abertura desta edição da Revista de Terapia Ocupacional da USP pudesse trazer contribuições para a discussão sobre a importância do trabalho na construção da saúde dos sujeitos e, consequentemente para as práticas desenvolvidas pelos Terapeutas Ocupacionais na contemporaneidade.

Diante disso, em dezembro de 2014(1), realizouse uma entrevista com Christophe Dejours - Psiquiatra, Médico do Trabalho, Ergonomista, Psicanalista, Professor Titular da Cátedra "Psicanálise, Saúde e Trabalho" do Conservatoire National des Arts et Métiers (CMAN) - Paris, França e membro do laboratório "Psicologia Clínica, Psicopatologia e Psicanálise" da Université Paris Descartes (Paris V) - Paris, França. Atualmente é considerado uma das principais referências internacionais no campo da Saúde Mental e Trabalho.

Antes de iniciarmos a entrevista propriamente dita, contextualizamos o Prof. Dejours com relação à origem da Terapia Ocupacional, suas grandes áreas de atuação e as questões que têm nos mobilizado mais recentemente com relação às práticas desenvolvidas na interface com o campo "Saúde e Trabalho". Realizou-se quatro grandes questões norteadoras ao pesquisador que, livremente, pôde discorrer sobre elas.

Para elaboração das questões iniciais, partimos de obras do próprio autor. Em muitas delas, por exemplo, o Prof. Dejours apresenta definições do termo trabalho tendo como base pressupostos da Psicopatologia e da Psicodinâmica do Trabalho, disciplinas em desenvolvimento desde as décadas de 1950 e 1980 respectivamente, das quais ele constitui- se como um dos grandes expoentes. Mais especificamente na obra intitulada "Trabalho Vivo - Tomo II: Trabalho e Emancipação $o^{(2) ", ~ o ~ p e s q u i s a d o r ~ a f i r m a ~ q u e ~ " O ~ t r a b a l h o, ~ n o ~}$ que ele tem de essencial, não pertence ao mundo visível”. Pedimos então, que o autor pudesse esclarecer ou melhor, explicar, de forma mais detalhada, qual era sua ideia central em torno desta definição.

Ainda nesta obra, o Prof. Dejours afirma que o trabalho seria o principal contexto da vida no qual podemos exercitar a democracia. Defende, igualmente, a tese de que o trabalho impulsiona processos de subjetivação, a realização de si e a construção da saúde. Solicitamos então, que ele pudesse nos explicar quais são, na perspectiva dele, os papeis que o trabalho desempenha na vida das pessoas, bem como sua importância.

Em seguida, aproximando a discussão do mundo do trabalho das problemáticas em destaque no contexto brasileiro (tomando como base dados dos anuários estatísticos da Previdência, por exemplo), pontuamos que desde a década de 1990 observamos, além do elevado número de afastamentos por acidentes e doenças osteomusculares, aumento significativo do número de pessoas que adoece mentalmente em decorrência do trabalho. Soma-se a isso o uso progressivo de substâncias psicoativas nos ambientes laborais. Tratam-se não apenas de drogas ilícitas, como o álcool, mas também dos medicamentos psicotrópicos, como ansiolíticos, por exemplo. Questionamos o pesquisador sobre quais eram suas hipóteses explicativas para este fenômeno.

Paraconcluir, o questionamos sobre as possibilidades que os profissionais que atuam especificamente na saúde

*Tradução Francês - Português: Juliana de Oliveira Barros e Selma Lancman.

1. Doutora em Ciências da Reabilitação pela Faculdade de Medicina da Universidade de São Paulo (FMUSP). Terapeuta Ocupacional do Curso de Terapia Ocupacional da FMUSP.

2. Pós-Doutora em Psicodinâmica do Trabalho pelo Conservatoire National des Arts et Métiers, CNAM - Paris, França. Profa. Titular do Curso de Terapia Ocupacional da FMUSP.

(1) Entre os meses de setembro de 2014 e fevereiro de 2015, Juliana Barros estava na França em decorrência da realização de estágio de pesquisa, no contexto de um doutorado sanduíche. Neste período, já envolvida na organização do I Colóquio Brasileiro de Terapia Ocupacional, Saúde e Trabalho e também deste dossiê temático, foi possível conceber a realização da entrevista e negociá-la junto ao pesquisador. No momento da entrevista a Profa. Dra. Selma Lancman pôde estar presente e participar da realização da mesma.

(2) Obra traduzida e publicada em português em 2012 pela Editora Paralelo 15. É composta por dois volumes (Tomo I: Sexualidade e Trabalho e Tomo II: Trabalho e Emancipação). Nela, Dejours, a partir da discussão com as obras de múltiplos interlocutores, apresenta os aspectos epistemológicos da Psicodinâmica do Trabalho. 
do trabalhador possuem para fazer frente à questão dos adoecimentos mentais relacionados ao trabalho: estratégias de enfrentamento, possibilidades de retorno e permanência no trabalho desta população e, por fim, a importância/ necessidade deste processo mesmo quando o contexto de trabalho não se mostra favorável.

A seguir apresentamos texto síntese, produto desta entrevista com o Prof. Christophe Dejours.

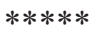

\section{Christophe Dejours}

Quando eu digo que o trabalho não pertence ao mundo visível, trata-se, evidentemente, de uma preocupação em relação à objetivação dele. Isso porque introduziu-se, ao longo dos últimos anos, métodos de avaliação no mundo do trabalho. Tratam-se, mais precisamente, das avaliações objetivas, quantitativas e por medida que colocam o problema do visível e do invisível. Mensura-se apenas aquilo que se pode ver, ou seja, se não é visível, não é possível de ser mensurado. E o trabalho, essencialmente, não pertence ao mundo visível por que, fundamentalmente, o trabalho é subjetivo.

Como diz Marx, o trabalho é vivo, individual e subjetivo. A subjetividade não pertence ao mundo visível e, em decorrência disso, não é mensurável. Não medimos sofrimento, prazer, amor, raiva, ódio. Isso não pode ser medido. Podemos caracterizá-los qualitativamente em certas condições; podemos perceber que existe agressividade, que há transformação de amor em ódio, mas a quantidade é uma metáfora.

Então, o trabalho é invisível pois ele é essencialmente subjetivo..., mas o que quer dizer o trabalho ser essencialmente subjetivo? Isso é decorrente do fato, como bem mostraram os ergonomistas nestes últimos 50 anos, de que existe sempre um hiato entre o trabalho prescrito - a tarefa, e o trabalho real - o trabalho efetivo. O hiato é irredutível porque o trabalho prescrito ou a organização prescrita do trabalho repousa sobre um postulado de previsibilidade do processo de trabalho, fundado nas ciências da organização do trabalho, nas ciências da engenharia, que reinam sobre o mundo do trabalho desde Taylor, no fim do século XIX.

Este postulado repousa sobre a ideia de que podemos prever o desenvolvimento, as etapas do processo de trabalho. A experiência do trabalho sob a luz da ergonomia e mais recentemente da análise clínica do trabalho, mostram que esta previsibilidade é colocada em cheque pela ocorrência de incidentes, de panes, de bugs, de anomalias como por exemplo os acidentes do trabalho...é o que chamamos de real do trabalho. A experiência do real do trabalho se manifesta sob a forma de fracasso do trabalhador... fracasso de seu saber técnico, de sua habilidade, de seus conhecimentos... e se formos ainda mais longe, isso recoloca em questão a ciência, incluindo as ciências da engenharia, pois o processo de trabalho não acontece como o engenheiro previu.

O problema que é colocado frente ao real do trabalho reside no fato de que o trabalhador seja capaz de inventar a solução. É necessário que ele encontre a solução por ele mesmo. A inteligência que é mobilizada para preencher o hiato entre o trabalho prescrito e o trabalho efetivo, isso é o mistério do trabalho. Trata-se da inteligência que vai ser estudada mais especificamente pela clínica do trabalho, pela Psicodinâmica do Trabalho e que não é estudada pela Ergonomia... trata-se de algo realmente específico à clínica e a Psicodinâmica do Trabalho.

É uma inteligência que se caracteriza pelo fato de passar por uma série de etapas, mas um aspecto fundamental é que ela começa pelo fracasso: trabalhar é fracassar. Em seguida, é ser capaz de suportar o fracasso, de não se render frente a ele, mas de se confrontar com o real que sempre resiste até o momento em que encontramos a solução. Isso pode durar alguns minutos em alguns casos, algumas vezes são muitos dias, outras vezes algumas semanas, muitos meses... eventualmente existem mesmo aquelas situações de trabalho onde são necessários muitos anos para conseguir resolver o problema.

Isso é verdade evidentemente para o trabalho do pesquisador, mas também é verdade para muitas profissões, como por exemplo a terapia ocupacional, a psicologia... é preciso muito tempo para encontrar as habilidades, para inventar soluções que vão permitir superar as dificuldades que o doente mental opõe às habilidades do terapeuta, por exemplo. São necessários muitos anos de formação e outros de experiência, mesmo após a formação concluída, para desenvolver as habilidades que vão permitir superar certas dificuldades com as crianças, adolescentes e adultos doentes, por exemplo.

É necessário então, ter a capacidade de suportar a experiência de fracasso. A resistência é o problema fundamental. Ela supõe, na realidade, que a subjetividade esteja engajada no trabalho não somente durante o tempo de trabalho, mas também fora dele.

Quando, por exemplo, se passa um dia inteiro tentando resolver um problema e não se consegue: com um doente em um serviço de medicina interna, em um serviço de psiquiatria, de gerontologia ou de oncologia infantil etc., e constatamos que os cuidadores não somente pensam no trabalho durante o tempo em que estão nele, 
mas continuam pensando no problema quando saem do trabalho... e que isso ainda faz parte do trabalho e que pode haver consequências para os familiares e, no final isso pode desencadear insônias... isto faz as pessoas sonharem durante a noite. O que tem nos mostrado a clínica, somada a uma análise mais refinada do ponto de vista teórico em relação ao que acontece nesta resistência no trabalho, é que a subjetividade inteira deve ser habitada pelo trabalho até que se forme uma intimidade com o corpo, uma familiaridade entre o corpo e o real do trabalho.

E finalmente, o lugar onde reside a inteligência no trabalho não é como se acreditava, ou seja, no cérebro unicamente. É preciso vivenciar/provar afetivamente a relação com o real e, para isso é necessário um corpo... a inteligência tem seu lugar no corpo por inteiro, seja na condução de uma central nuclear, seja para pilotar um avião de caça, para cuidar de um doente. É necessário aprender a sentir o doente e quando somos professores é necessário aprender a sentir o público, o anfiteatro. É complicado esta relação de intimidade do corpo, mas é ele que experimenta o real e é a partir dele que se inicia, que se coloca em movimento o processo que vai conduzir a descoberta da astucia e o desenvolvimento de estratégias que vão permitir superar o real.

Falando em termos mais refinados, é o corpo que intui a solução, aquela que permite superar o real. E esta intuição, esta potência da intuição do corpo é conferida inicialmente pelo estabelecimento da familiarização do corpo com o real. Esta familiarização é subjetiva e em primeiro lugar, fundamentalmente afetiva. E no final a solução chega, ela vem como ideia, quase como uma ideia incidental... Freud diria “Einfall'! Tal ideia, de repente, vai permitir tentar alguma coisa que não se teria sabido fazer até aquele momento.

Esta inteligência que reside no corpo está à frente da nossa capacidade de compreendê-la. Isto é complicado... nós somos capazes de desenvolver habilidades no trabalho que nós não temos a capacidade de dar uma explicação exata, seja verbal ou por escrito... nós não seríamos capazes de explicar no que consiste esta habilidade, por exemplo: o que é o tato com um doente? O que é sentir um anfiteatro para um professor, o que isso quer dizer? Mesmo para as pessoas que fazem isto há muito tempo é extremamente complicado compreender a habilidade que elas usam para poder manter este contato com seu público. Elas sabem fazê-lo, mas não sabem explicar como fazem.

Esta inteligência está à frente da conceituação, da formalização que nós podemos fazer dela. Tudo o que acontece na subjetividade, as insônias, as mudanças de humor, a irritabilidade, todos os afetos fazem parte do trabalho, os sonhos fazem parte do trabalho. Os sonhos são um tempo particular no qual o que, inicialmente, se coloca entre o corpo e o real, encaminha-se durante a noite e, através do trabalho do sonho, inicia-se a transformação da relação entre o sujeito e seu corpo. É o que chamamos o trabalho do sonho " l'arbeit »! Este trabalho do sonho é uma condição necessária para que possa surgir a intuição e a solução.

Então o trabalho do sonho é o tempo do trabalho de si sobre si, que é gerado a partir da relação entre o corpo e o real. E é por isso que ela se configura enquanto sofrimento pois, inicialmente, não funciona. Dispara um segundo trabalho, desta vez na subjetividade e, da relação entre o sujeito e a maneira como habita seu corpo nasce a solução. Tudo isso pertence à subjetividade. Portanto, a genialidade da inteligência no trabalho é inteiramente subjetiva. Por isso ele, o trabalho, pertence ao mundo invisível. E o essencial do trabalho, da inteligência do trabalho, não pertence ao mundo visível e não será nunca mensurável. A partir desta compreensão, defino o trabalho como aquilo que o sujeito deve acrescentar à organização prescrita para poder fazer frente ao que não é previsto pela organização do trabalho, para fazer face ao real.

E isso é o trabalho, a passagem pela subjetividade... este longo circuito pelo qual chegamos finalmente a intuição da solução que é, na verdade, um desenvolvimento da inteligência. Caminho que passa pelo corpo, pela inteligência, insônia, sonhos... pela transformação da relação de si consigo mesmo. É isso que nós chamamos de Trabalho Vivo. Então, de forma geral, o trabalho é aquilo que é necessário acrescentar ao prescrito para que o sistema funcione. O Trabalho Vivo é o que isso implica do ponto de vista da inteligência e da mobilização da subjetividade. O Trabalho Vivo é o que é preciso acrescentar, ou seja, o que se deve acrescentar de si para alcançar este resultado: a inteligência e a subjetividade. Finalmente, o aspecto necessário à mobilização desta inteligência é o que nomeamos tecnicamente de zelo. Eis o que é o Trabalho Vivo!

E é este Trabalho Vivo que nenhuma organização do trabalho pode dispensar, nenhuma organização do trabalho pode prescindir. Se as pessoas executam as ordens da organização do trabalho isto não funcionará por causa dos incidentes, das disfunções... pelas panes e imprevistos impostos pelo real.

Se não há ninguém preparado para o inesperado, então o trabalho é interrompido. Em alguns casos ele para, em outros, explode, como nas centrais nucleares e empresas petroquímicas, por exemplo. Se não há o Trabalho Vivo, o risco é o dos incidentes e até mesmo os acidentes, e ainda as grandes catástrofes industriais como nós vimos em diferentes setores, diferentes situações... Chernobyl por exemplo, a grande catástrofe nuclear, é fundamentalmente resultado de uma desmobilização do Trabalho Vivo. 
Então porque que nós dizemos que o trabalho contribui na construção e fortalecimento da subjetividade? É fundamentalmente em decorrência deste processo do Trabalho Vivo que passa pela inteligência. Na realidade, num primeiro momento, trata-se desta relação afetiva e subjetiva com o real, portanto esta familiarização pelo engajamento do corpo na relação com o real. E eu especifico agora que o corpo em questão não é o corpo biológico, é o que chamamos de segundo corpo. Se nós não temos uma teoria do corpo nós não podemos absolutamente compreender como isso funciona. Não é o corpo biológico, os captadores sensoriais ou sensitivos, não somente o cérebro. Trata-se do corpo que experimenta a vida: é o corpo subjetivo que nós opomos ao corpo objetivo. As pessoas que têm um diagnóstico de esquizofrenia, por exemplo, elas têm um corpo objetivo que funciona muito bem, você mede a frequência cardíaca, a pressão arterial, a imunologia, tudo funciona bem, mas o corpo não é habitado pelo esquizofrênico, o corpo subjetivo não funciona bem para algumas pessoas.

Portanto, o corpo objetivo, o corpo fisiológico, e o corpo do vivido, o corpo subjetivo, não são os mesmos. $\mathrm{O}$ que está no trabalho refere-se ao corpo subjetivo, que não se vê, mas se experimenta de modo afetivo ... por meio dele se sofre, mas também em certas condições, se transforma este sofrimento em prazer. Este primeiro momento da relação entre o corpo subjetivo e o real do trabalho é retomado num segundo momento pelo trabalho de si sobre si que integra o trabalho efetivamente realizado. O segundo tempo é uma verdadeira transformação de si sobre si por que, para que venha a solução, para que venha a ideia que vai permitir superar o real é preciso passar por uma transformação da maneira de habitar o próprio corpo. E, portanto, é um processo transformador pelo qual, em razão da existência do real, eu sou incitado, eu sou movido a me transformar. Então trabalhar não é somente produzir é também transformar a si mesmo. E ao final do processo nós somos mais hábeis, formamos uma nova habilidade que não existia antes do trabalho. Ela é uma produção e uma consequência da relação de obstinação e de resistência frente ao real.

Deste modo, a habilidade não existe antes do trabalho, a competência não existe antes do trabalho. É o confronto com a impotência, com o fracasso no trabalho que vai me obrigar a me transformar até que eu adquira, até que eu descubra e que se revelem em mim novas habilidades que não existiam antes. Portanto, pela obstinação da relação com o real eu sou, ao final do circuito, mais inteligente e mais hábil em relação ao que eu era até então.

Assim sendo, o real do trabalho possibilita uma transformação dos sujeitos que os torna mais inteligentes do que antes. E mais, nesta relação com o real do mundo e o que resiste ao domínio, eu não descubro somente o mundo tal como ele é, ou seja, não é somente o mundo que se revela a mim, novos registros de sensibilidade também aparecem em mim... a força de trabalhar a madeira, a dificuldade de manejar os instrumentos, as serras, as lixas, por exemplo, fazem com que após anos de trabalho meu corpo seja capaz de sentir coisas que ele não sentia antes de ter feito o trabalho.

Portanto a sensibilidade aumenta, novos registros de sensibilidade que não existiam antes aparecem, e é graças a esta confrontação no trabalho que estas novas formas de sensibilidade se desenvolvem. É extraordinária a possiblidade de aumentar os registros de sensibilidade. Isso é o que chamamos de construção e fortalecimento da subjetividade. É o maior prazer que nós podemos ter. É também um aumento do poder do corpo de experimentar e de se experimentar. Portanto é também o ponto de partida de um grande amor de si. O amor por si mesmo é o fundamento da saúde mental. É isso que está em xeque na relação entre subjetividade e trabalho.

Nós poderíamos dizer mais sobre esta questão do "construção e fortalecimento da subjetividade", do aumento da inteligência e do amor de si. Poderíamos ir até a ampliação / fortalecimento da identidade que passa não somente pela relação de si sobre si, mas supõe que o trabalho que eu realizei seja submetido ao olhar do outro, dos colegas, dos superiores hierárquicos, dos subordinados, dos clientes, ou seja, daqueles que vão se beneficiar do meu trabalho. Entramos, neste momento, no registro do reconhecimento pelo olhar do outro, que tem um grande poder sobre a construção da identidade e da saúde mental.

Se nos beneficiamos dos diferentes julgamentos constitutivos do reconhecimento no trabalho, podemos transformar o sofrimento no trabalho em prazer no trabalho. Trata-se do prazer relativo ao fortalecimento da identidade. Não se refere, neste momento, apenas a construção da subjetividade como eu disse até agora... falamos da identidade no sentido psicológico do termo (em contraposição ao sentido sociológico do termo). Ou seja, o fato de eu ser capaz de me reconhecer enquanto continuo, mesmo diante de todas as mudanças que faço ao longo da vida. Trata-se de mim mesmo constituindo minha própria identidade.

Para a maioria das pessoas ela, no término da adolescência, não está concluída, findada, estável, completamente madura. Houve impasses na construção desta identidade e, toda doença mental, toda crise psicopatológica é centrada em uma crise de identidade. De repente duvidamos do que somos, da continuidade e do reconhecimento de nós mesmos... ou seja, temos dúvidas para afirmar esta identidade... e a maioria de nós precisa do 
olhar do outro para isso. E o trabalho é uma oportunidade de mobilizar o olhar do outro não sobre mim diretamente, mas sobre a produção do meu trabalho.

O olhar direto sobre mim vem do amor. É uma das formas de construção da identidade. O olhar sobre o que eu produzo é o reconhecimento. Na verdade, uma modalidade específica de reconhecimento que não é sobre mim, mas sobre o que eu produzo, ou seja, sobre o meu trabalho, portanto um olhar sobre o fazer. Este é um meio muito potente de fortalecer a identidade. Entretanto, é necessário repatriar este julgamento que se dirige para o meu fazer... repatriá-lo no registro do ser, que é uma tarefa específica de cada um: me sentir mais inteligente, mais amável, mais sólido... é o que chamamos de realização de si no campo social.

Agora, vem a questão do trabalho, o principal contexto da vida onde podemos exercitar a democracia. Esta é uma questão central do trabalho, mas exige que passemos agora a uma outra dimensão do trabalho, que não é mais a do trabalho individual e subjetivo, mas é o trabalho coletivo e a inteligência no plural. Trata-se de um longo percurso a ser feito para compreendermos o que é a inteligência no plural, coletiva, porém, já destaco que encontramos nela o mesmo hiato que tínhamos no nível individual entre tarefa e atividade, exceto que no nível coletivo temos um hiato entre coordenação e cooperação. Ou seja, se as pessoas respeitassem as ordens dadas pela hierarquia sobre a maneira de trabalhar junto, a maneira de organizar o trabalho conjunto, isso não funcionaria. As pessoas reinventam coletivamente uma outra maneira de trabalhar que nós chamamos de cooperação. A tarefa está para a atividade assim como a coordenação está para a cooperação.

A cooperação, ela repousa sobre a capacidade das pessoas de interpretarem as ordens, a organização prescrita... Porém, uma interpretação compartilhada pela equipe. Para chegar a uma interpretação compartilhada e, finalmente, "trapacear" juntos de forma que a organização prescrita se efetive, se torne eficiente, eficaz, são necessárias algumas condições fundamentais. É necessário a abertura de tempo e espaço no interior das organizações do trabalho para que os trabalhadores possam confrontar, discutir, debater sobre a forma como cada um desenvolve seu trabalho; sobre como cada um interpreta individualmente as prescrições, com vistas a caminhar para a compreensão, para a concórdia, modalidades de acordos e combinados entre diferentes membros de uma equipe ou de um coletivo de forma a construir uma interpretação comum das ordens e, então, um modo operatório comum.

Isso demanda que as pessoas que compõem uma equipe tenham tempo e espaço para discutir... chamamos isso de espaço de deliberação no qual há confrontação sobre os diferentes modos operatórios, sobre as diferentes opiniões dos trabalhadores com relação a maneira de interpretar a organização prescrita do trabalho.

Este espaço de deliberação é estruturado como um espaço público. Nele, é necessário, não apenas confrontar pontos de vista sobre a eficácia de modos operatórios ou de diferentes interpretações sobre as prescrições, mas também apresentar os argumentos que não vem apenas da eficácia, mas sim da preferência de cada trabalhador sobre uma certa forma de interpretar.

Os mais idosos e os mais jovens não têm o mesmo ponto de vista sobre a maneira de trabalhar. Em função de seu sistema de valores, de sua posição ideológica, posições políticas, não temos o mesmo ponto de vista sobre as estratégias que devemos desenvolver. Portanto, os argumentos que devem ser trocados pelas pessoas, constituem-se como argumentos mistos: eles são inicialmente técnicos, sobre a eficácia... mas há também uma segunda dimensão que tem origem na ética e na política... e não na eficácia, mas sobre as noções de bem e mal, justo e injusto, distribuição igualitária, etc.

Estes aspectos não estão ligados ao mundo objetivo, mas a outras racionalidades, tais como a racionalidade moral e prática de um lado e, racionalidade subjetiva, relacionada à proteção, à realização de si e à manutenção da saúde, de outro.

Temos perspectivas distintas por que não temos a mesma idade, o mesmo sexo, as mesmas conformações físicas. Os altos e os baixos não têm necessariamente a mesma opinião... se sou diabético ou tenho alguma deficiência... eu não tenho as mesmas expectativas, as mesmas escolhas, as mesmas preferências sobre a maneira de trabalhar porque devo levar em conta os limites que não são os mesmos para todos. Este espaço de deliberação no qual as pessoas confrontam seu ponto de vista que é misto - uma parte que se refere à eficácia e outra não - configura uma confrontação de opiniões. Na teoria, argumentos mistos configuram-se como opiniões.

A confrontação de opiniões com o propósito de se chegar a um acordo entre os membros, um consenso sobre aquilo que se refere a todos, é o que chamamos de espaço público. É, desde Aristóteles, o espaço público que está no coração da gestão da cidade, ou seja, fundamentalmente as responsabilidades dos cidadãos e então, a construção da civilidade no espaço público... a maneira pela qual as pessoas vivem juntas... é o viver junto, a cidadania, a cultura.... todas estas coisas são responsabilidades coletivas que dizem respeito, portanto, a todos nós.

No trabalho, o espaço de deliberação é construído da mesma forma que no espaço público da 
gestão das questões políticas da cidade. E o trabalho é a oportunidade, a mais ordinária, de aprender a se implicar no exercício democrático. Para que o espaço de deliberação funcione, para que as pessoas consigam produzir acordos e, finalmente, as regras do trabalho, o que chamamos tecnicamente de atividade deôntica... para que esta atividade deôntica seja possível, é necessário que as pessoas falem dos respectivos trabalhos, testemunhem acerca do seu trabalho e, ao mesmo tempo, é necessário que elas sejam capazes de justificar as razões pelas quais elas preferem trabalhar de determinada forma.

Trata-se, portanto, de uma tomada de palavra / posição arriscada e, por ouro lado, é necessário que as pessoas aprendam a escutar as razões dos colegas, dos outros trabalhadores, porque preferiram esta ou aquela maneira de trabalhar e não a minha. É um espaço de circulação da palavra, de tomar a palavra para si, mas também de escutar, dinâmica que está, fundamentalmente, no coração do exercício da democracia. É por isso que o trabalho pode ser um espaço de aprendizagem do exercício da democracia único e, evidentemente, muito comum.

Se este espaço não funciona no mundo do trabalho, se não há espaço de deliberação porque houve uma interdição dos espaços de fala, é a democracia que deixa de ocorrer no mundo do trabalho e subitamente não há mais acordos entre as pessoas, não há mais a constituição de regras do trabalho. Isto quer dizer, é a antidemocracia, é o cada um por si. Nessa hora parte-se para a competição desleal, « os golpes baixos » e nesse caso entramos no mundo da degradação da democracia. Dessa forma, não há neutralidade do trabalho diante da democracia. Ou a gente gera um processo que favorece a democracia ou ele a destrói. É o que chamamos da centralidade política do trabalho.

Em relação a questão das substancias psicoativas, é simples, quer dizer... existe um nova forma de organização do trabalho do qual já falamos, especialmente a avaliação individualizada de performance que introduz a concorrência generalizada e desleal entre os colegas. Isso leva ao "cada um por si", de tal maneira que finalmente o sucesso, a vitória do meu colega é ruim para o meu futuro. Se a avaliação individualizada de performance coloca em concorrência todos contra todos, aquele que tem um bom resultado do meu lado, passa a ser uma ameaça para mim, então a cooperação da qual falamos é destruída, assim como o viver junto. E também tudo que dissemos sobre a democracia desaparece e, finalmente, o respeito pelo outro, a ajuda, a união e a solidariedade desaparecem.

Então, quanto estamos em uma relação de «cada um por sì e que, portanto, a avaliação funciona também como uma ameaça de sanção, de possíveis demissões porque eu tenho performances piores que as do meu colega, vemos que a solidão, a exaltação da performance individual faz com que as pessoas se engajem em um processo no qual elas trabalham mais e mais.

No final, não há meios de regular coletivamente este engajamento no trabalho. É onde ocorre a explosão das patologias da sobrecarga. As patologias de sobrecarga são os distúrbios osteomusculares (LER/DORT), o karoshi, o burnout, mas também a questão do doping. Quer dizer, para fazer frente a solidão, ao sofrimento no trabalho, a sobrecarga, ao medo, ao medo dos outros, mas também ao medo de não conseguir manter a cadência, as pessoas recorrem cada vez mais a substancias psicoativas para manterem a performance.

Começa com os calmantes, ansiolíticos, substâncias psicotrópicas em geral, para que não se adormeça, mantendo a hiperatividade. Para isso utilizamos, por vezes, substâncias como o café, o álcool ... porque o álcool, a depender da dose, é calmante ou excitante então, existem pessoas que fazem uso da substância para se estimular... café, chá mais também, eventualmente, cocaína, crack, etc. Então, há uma utilização cada vez mais frequente de substâncias psicoativas que agravam as patologias de sobrecarga por que, finalmente, as pessoas vão tentar ir além do limite do corpo fisiológico e do que suas capacidades psíquicas as permitiria fazer. E existe um consumo cada vez mais importante de substâncias psicoativas com a anuência dos laboratórios farmacêuticos, frequentemente dos médicos que prescrevem essas drogas, onde talvez seria melhor considerar um afastamento do trabalho para que as pessoas pudessem repousar.

Porém, a utilização de substâncias psicoativas é algo muito antigo... isso acontece há muito, muito tempo. $\mathrm{O}$ uso do álcool para encarar o medo no trabalho, isso acontece há muito tempo. Começou com os caçadores, soldados, acontece também na polícia. As pessoas bebem para fazer frente ao medo... isso não é novo. O que muda é que existe cada vez mais uma diversidade de produtos e substâncias que são colocadas no mercado. Aliás, é um mercado enorme que é, ele mesmo, fonte de benefício considerável para as indústrias farmacêuticas e químicas que, por vezes, crescem com base nele. Estamos, portanto, dentro de uma conjugação dos efeitos de uma nova forma de organização do trabalho de um lado e, por outro, os benefícios que isso traz para a indústria farmacêutica. É isso é muito sério.

Agora falando sobre as possibilidades para os profissionais da reabilitação frente ao problema da relação entre saúde mental e trabalho.... Eu vou me permitir responder de forma muito precisa a esta questão. Existe, evidentemente, um esforço que deve ser feito... é um esforço clássico o da reabilitação de cada indivíduo 
que adoece, de cada indivíduo que apresenta alguma deficiência ou uma patologia física, sensorial ou psíquica. Existe um período de readaptação individual no trabalho. É fácil falar, mas muito mais difícil fazer.

Pode-se designar um alvo que é o desenvolvimento de competências e habilidades de um paciente ou uma pessoa com deficiência que permite compensar o déficit sensorial, motor ou psíquico. É o que chamamos de princípio vicariante. É um princípio que já funciona no corpo biológico, quer dizer, se meus rins não funcionam bem na eliminação dos derivados ácidos do sangue, eu posso "aumentar a ventilação" e eliminá-los pela via respiratória. Então, há uma compensação do déficit dos rins pela função respiratória. Isso pode funcionar da mesma forma de modo inverso: se tenho uma dificuldade respiratória, uma insuficiência que faz aumentar a quantidade de ácidos no meu sangue ou que faz baixar o $\mathrm{PH}$, são os rins que vão eliminar os derivados ácidos pela urina. A compensação de um pelo outro, de uma função por outra, se chama princípio vicariante em fisiologia.

Da mesma forma, se eu não enxergo bem, mesmo se sou cego, tento compensar uma parte do déficit visual pelo desenvolvimento de capacidades auditivas que uma pessoa sem este déficit não possui. Portanto, existe um trabalho a ser feito junto as pessoas com deficiência para desenvolver estas possibilidades de compensação de um déficit por outra função do corpo humano. Mas isso não é suficiente. Para que alguém que apresenta uma deficiência física, sensorial ou um transtorno mental, possa trabalhar, na realidade, o aspecto central não é somente a organização do trabalho; é fundamentalmente a questão da cooperação.

Sendo assim, a ação do Terapeuta Ocupacional (TO) não pode se ater unicamente ao trabalho sobre os indivíduos. A questão que se coloca seria: quais são as condições da cooperação para que possamos dar lugar a diferença particular que representa, por exemplo, uma pessoa com deficiência sensorial. Mas a pessoa com deficiência sensorial é aquela que adoeceu ou que teve um acidente de trabalho, mas é também aquela que simplesmente envelheceu. Quando envelhecemos, temos algumas perdas, alguns déficits... a gente muda.

Se somos homens ou mulheres, não temos as mesmas competências então, é na cooperação que podemos encontrar os melhores acordos entre os diferentes membros de uma equipe para que todo mundo encontre e tenha um lugar. Sendo assim, o trabalho de readaptação supõe investimento no espaço de cooperação, quer dizer, nos espaços de deliberação. É necessário a ocorrência da deliberação entre os membros do coletivo para poder abrir espaço e encontrar acordos que vão permitir que todos trabalhem, incluindo as pessoas com deficiência, por exemplo. Se não há um cuidado coletivo com o viver junto, com a solidariedade, a ajuda mútua, não existem possibilidades de concretização deste processo.

Acredito que a ação do TO não pode ser bemsucedida se a readaptação, a integração dos trabalhadores com deficiência no trabalho, por exemplo, seja de responsabilidade unicamente dele.

De um lado, há o trabalho do TO e, de outro, existe a questão da política das empresas em matéria de organização do trabalho. Se na instituição existe uma pessoa que tem dor nas costas, em um determinado momento, ao tencionar a organização do trabalho, as pessoas ali inseridas e que trabalham duro vão terminar por detestar aquele que tem dor. Então, isso depende da organização do trabalho e da política por trás dela, pois a organização do trabalho é igualmente uma escola política. A organização do trabalho é sempre uma estratégia de dominação. Existem diferentes formas de tratar a questão da política do controle social e da cooperação entre as pessoas. Existem diferentes maneiras de pensar a cooperação na organização do trabalho.

Nas formas do trabalho atuais, há uma vontade muito pulsante de destruir os fundamentos da cooperação. Evidentemente isso não é novo, Taylor já fazia isso... o problema dele era o de impedir a cooperação para individualizar as pessoas. Atualmente fazemos melhor que Taylor com os computadores, com a avaliação individual de performance, separamos ainda mais as pessoas... quanto mais caminhamos neste sentido, menos a solidariedade pode funcionar, torna-se impossível.

Sendo assim, você pode tomar como referência qualquer ambiente... um escritório, o funcionalismo público, a agricultura, a petroquímica... de acordo com o modo de organização do trabalho, nos tornamos progressivamente mais intolerantes. Inicialmente com as pessoas com deficiência, mas, em seguida, é com aquele que é mais lento, depois com as mulheres, depois são os idosos. Você observa pessoas com 45 anos... onde está onde a deficiência delas? Começa onde a deficiência? Começa onde decidiu a organização do trabalho. Se você não pode mais seguir a cadência, você já é mais velho... então você pode ser considerado velho aos 40 anos... e dentro de alguns setores de informática, por exemplo, aos 35 você é considerado velho... o declínio começa aos 35 anos e as pessoas não vão mais encontrar trabalho.

É verdade que as pessoas envelhecem e que elas são menos fortes fisicamente. Mas, no geral, a partir dos 10, 12 anos, a acuidade visual começa a reduzir, por exemplo e depois, se você toma como referências as outras performances, tudo começa a declinar. Mas justamente o que não declina é a inteligência. As competências 
aumentam ao longo do processo de envelhecimento de tal forma que o que eu perco do ponto de vista físicofisiológico, eu compenso - graças ao princípio vicariante - por habilidades maiores ainda. Além disso, como o trabalho não se dá somente por uma relação individual com a tarefa, mas a partir de uma relação que também é coletiva, os mais velhos tornam-se muito úteis pela sua função na equipe. Os jovens não conseguiriam de forma alguma assumi-la com a mesma competência.

Bom, existem muitas competências coletivas que não aparecem. Mas por tudo isso é necessária a existência de uma política que se ocupe disso. Existem empresas onde o que conta não é somente ter pessoas que cumpram as metas estabelecidas por hora ou por dia. Elas priorizam ter pessoas que fiquem durante 10,12 ou 15 anos no mesmo lugar!. Por que? Pois tenho um serviço de psiquiatria e que, para conseguir constituir uma equipe de psiquiatras, de psicólogos, de terapeutas ocupacionais, de educadores que são capazes de se responsabilizar por uma região com crianças, famílias, tenho necessidade de vínculos estáveis. Então, o problema da cooperação se coloca de forma muito diferente: a política da organização do trabalho visa que as pessoas estejam bem e felizes no trabalho, por que é por isso que elas vão permanecer por 15 anos.

O problema da cooperação se coloca de forma diferente. A política da organização do trabalho visa que as pessoas estejam bem. Caso contrário, elas vão partir, vão embora. Então, tudo depende da organização do trabalho. E a ação do TO, ela não tem nenhum sentido se não existir um acordo com os responsáveis da organização do trabalho. Se o chefe do serviço de medicina te diz que lá é como o exército, por exemplo, então não podemos trabalhar com ele pois no exército o que conta é a eficácia... se as pessoas morrem não importa. Esta concepção de organização do trabalho não tem nenhuma chance de possibilitar que a ação do TO seja bem-sucedida. A ação do TO depende da análise da demanda e da margem que se dispõe na discussão com as pessoas que são responsáveis pela organização do trabalho.

Se você quer montar um serviço hospitalar que, por sua natureza, demanda a permanência dos trabalhadores por longo período, você vai aumentar as competências das pessoas para que sejam progressivamente mais ávidas, com habilidades mais refinadas... isso supõe a gestão antecipada da permanência e investimentos significativos em matéria de cooperação. $\mathrm{O}$ que vai permitir às pessoas permanecerem não são apenas as performances individuais, mas sim o viver junto, a convivialidade, a cooperação. Se existe um que não está bem os outros o ajudam e quando eu não estou bem, ao invés de me afastar do trabalho, eu venho por solidariedade aos outros. Eu venho, mas os outros sabem que eu estou doente e aceitam que os dias em que estou doente eu trabalhe menos intensamente então, hoje sou eu, amanhã é você. Tudo isso se desenvolve nos coletivos de trabalho.

Tudo isso depende do que é o trabalho, de como o definimos. Então, em função da negociação com quem organiza o trabalho, não vale a pena o investimento do TO. É necessário analisar a demanda. Existem muitos serviços nos quais as pessoas estão abertas para que façamos esforços para tentar a integração das pessoas com deficiência, por exemplo. E isso pode funcionar muito bem por que a pessoa com deficiência, quando encontra seu lugar junto a um coletivo de trabalho, torna-se muito eficaz e contribui significativamente junto ao coletivo.

Então é por isso... ou você tem uma política de organização do trabalho que pensa a questão da cooperação e do coletivo, ou você tem uma organização do trabalho que demanda apenas performances individuais. É necessário avaliar se vale a pena estar nestas últimas para promover a readaptação.

Em contrapartida, existem empresas que se preocupam sobremaneira com o coletivo de trabalho, a duração, a performance, a fidelidade e nelas, a pessoa com deficiência tem realmente um lugar legítimo. Uma vez que ela tem um lugar, ela vai trabalhar e isso é uma vantagem para a empresa. A ação racional é a de analisar a política da organização do trabalho da empresa.

$\mathrm{Eu}$ acredito, finalmente, que o investimento significativo em matéria de cooperação, na política da organização do trabalho é um elemento que determina a qualidade do trabalho. $\mathrm{O}$ recurso fundamental da qualidade do trabalho e do progresso no trabalho é o coletivo e não os indivíduos. Os indivíduos são fundamentais, claro, mas a riqueza fundamental é a de trabalhar junto. Eu consigo mostrar isso em termos de qualidade, produtividade. Quanto mais você investe no coletivo mais você ganha. Quanto mais você investe no indivíduo mais você inibe a cooperação.

Então a ação e o sucesso da ação dos TOs ela depende: das pessoas que são responsáveis pela organização do trabalho nas instituições onde se está, mas ela depende também das políticas públicas. Se a política pública diz que o mais importante é a cooperação, você vai encontrar o lugar e os meios de reintegrar as pessoas no trabalho por que elas contribuem. Se você tem uma política neoliberal, torna-se mais difícil realizar o trabalho na medida em que é demanda a performance individual, o que não deixa espaço para a cooperação. 